\title{
Effect of Psychological well being, Death Anxiety and Depression On curable \& Incurable Disease Patients
}

\author{
Dr. Krishna J. Vaghela ${ }^{1}$
}

\begin{abstract}
:
The present study has been designed to investigate the difference of psychological well- being, death anxiety, depression between incurable and curable diseases patients. The study was conducted over a sample of eighty patients both incurable diseases patients and curable diseases patients. All participates were administered the psychological well- being scale, death anxiety scale and depression scale. Data was analyzed using t-test. The results reported that exists a statistically significant difference in psychological well-being between incurable and curable diseases patients. As regarding the death anxiety in curable diseases patients was not different significantly from that of patients with incurable diseases. Significant difference is also observed between incurable diseases and curable diseases patients as regarding to their level of depression.
\end{abstract}

Keywords: Diseases, patients, curable diseases, incurable diseases, death anxiety, depression, psychological well- being.

An incurable disease affects population worldwide. Incurable disease is also major cause of premature death, around the world. Patients with incurable diseases suffer in many aspects of their lives, including pain and other troubling physical symptoms psychological turmoil as well as existential distress

Mental and physical health and well-being interact and affected by a wide range of influences throughout life. The link between physical and mental health are clear. There are shared risk factors for illness regularly presents with both psychological and physical symptoms and being physical ill particularly on a chronic basis, often has an impact on mental health and psychological well - being. Some studies have been conducted on the relationship between negative emotions and depression, lifestyle, life expectancy with incurably sick people.

${ }^{1}$ Head \& Associate Professor, Department of Psychology, Yogiji Maharaj Mahavidyalaya, Dhari

(C) 2015 I K Vaghela; licensee IJIP. This is an Open Access Research distributed under the terms of the Creative Commons Attribution License (http://creativecommons.org/licenses/by/2.0), which permits unrestricted use, distribution, and reproduction in any Medium, provided the original work is properly cited. 


\section{Effect of Psychological well being, Death Anxiety and Depression On curable \& Incurable Disease Patients}

Depression and anxiety have both been individually associated with a higher risk of developing cardiovascular disease and in patients with these diseases (they are) associated with higher risk of recurrent cardiovascular events and death. Previous studies found that depression is associated with certain risk factors of metabolic syndrome, such as hyperlipidemia, obesity etc. Depression is not only a risk factor for cardiovascular disease but is also a strong predictor of mortality in patients with manifest ischemic heart disease (Ford et. al.1998). Many people with incurable diseases become depression. In fact depression is one of the most common complications of incurable diseases.

Incurable diseases are related to life style, choices and unhealthy behaviors. Patients react in a wide range of ways when dealing with anxiety about death. Heart disease and depression are commonly co morbid (Rudisch and Nemeroff 2003). Evidence from prospective healthy cohort studies had reinforced earlier concisions that anxiety and depression is associated with an increased risk of all cause mortality, (Takeshita et - al 2002, Wassertheil -Smoller et. al. 2004, Wusin et. al. 2005). According to maddi (1980) death anxiety arises not only by actual confrontations with death but also from experiences of unvented endings limitations of time energy or disproved ideals that threaten the reining of life. Jogsan (2002)found significant difference between healthy person and incurable diseases patients. A 2009 study of patients with severe chronic obstructive pulmonary disease found that 22percent of the participants had at least mild depression, defined as a score of 14 or more on the widely used Beck depression inventory seventeen percent were taking antidepressants determinant of health related quality of life. Mehnert and Koch (2011) found that death acceptance and psychological stresses fighting style and life quality have an impact on health. Some studies have been conducted to compare death attitude among patients with different diseases. Most of incurable disease patients would experience more sever mental problems such as depression, anxiety, stress, frustration etc. Incurable discuses are often associated with a great deal of psychological distress, depression, anxiety and affecting quality of life as well as well being. Therefore the aim of the present research was to investigated the effects of psychological well - being, death anxiety, depression in incurable and curable disease patients. 


\section{AIM AND OBJECTIVES:}

The main purpose of the present research was to find out the difference of psychological well being, death anxiety and depression between incurable and curable diseases patients. Some of the major objectives were framed to study the problem.

- To investigate the psychological well being between incurable and curable diseases Patients.

- To investigate the death anxiety between incurable and curable diseases patients.

- To investigate the depression between incurable and curable diseases patients.

\section{HYPOTHESES:}

Keeping view the objectives of the present study following null hypotheses framed for the present research.

- There will not be any significant difference between incurable and curable diseases patients for their score of psychological well being.

- There will not be any significant difference between incurable and curable diseases patients for their score of death anxiety.

- There will not be any significant difference between incurable and curable diseases patients for their score of depression.

\section{METHODOLOGY:}

In the present study achieve the above cited objectives, survey method was conducted by the researcher to collect relevant data regarding the present research.

Participants :The participants of the present research shall be 100 subjects, total 140 data fill up from different areas as well as hospitals of ( Rajkot city ) in which randomly selected eighty data. However patients group represented different areas of Rajkot city. Sample were selected through purposive sampling technique out of which 40 incurable disease patients and 40 curable disease patients ( age range 25 to 60) patients were identified as per clinical details and diagnosis. The sample was consisting of only male patients.

Instruments: The following standardized tools were used for the present research.

To measure psychological well being of subjects, the psychological well-being scale by Sudha Bhogle was used. The reliability of the test is 0.81 and validity is high. To measure death 


\section{Effect of Psychological well being, Death Anxiety and Depression On curable \& Incurable Disease Patients}

anxiety, Death Anxiety Scale by Thakur was used. The reliability of the test is 0.86 and validity is 0.75. To measure depression Back Depression Inventory ( B D I ) was used.The test retest reliability for B D I is 0.80 and Validity 0.66.

Procedure: The present research conduct on 80 patients both incurable disease and curable disease. All the respondents voluntarily participated in the present research. After establishing report with the participants the questionnaires were administrated (their convener times) with the necessary instruction and data was collected. All the participants were assured that their responses could be kept confidential. After the compellation of the whole information was statistically analyzed.

Statistical Analysis: The researcher put the data edited and coded together in a carefully designed table for statistical analysis t-test was applied to see the significance of the difference between incurable diseases patients and curable diseases patients. On the basis of their psychological well being,, death anxiety, depression scores.

\section{RESULT AND DISCUSSION:}

The main purpose of the present research was to find out the difference of psychological wellbeing, death anxiety and depression between incurable and curable diseases patients. The research findings are based on the responses of eighty incurable and curable diseases patients. Ttest were conducted to examine the differences in psychological well- being between incurable and curable diseases patients. The first hypothesis "There will not be any significant difference between incurable and curable diseases patients for their score of psychological well- being." Table -1 gives the descriptive statistics for each of two groups on psychological well- being (as defined by incurable and curable diseases patients). This t-test revealed statistically significant difference between the mean number of two comparative groups, were group-1 has ( $M=21.89)$ and group-2 has $(M=19.93)$. From Table-1 reveal that there is significant difference in the mean score of psychological well- being of comparative groups as the t-value (4.4) is found to be significant at 0.01 level. The difference in the psychological well- being of incurable and curable diseases patients is statistically significant hence the null hypothesis is rejected, and it clearly indicates that the curable diseases patients had better psychological well- being as compare to incurable diseases patients. Ho -2 There will not be any significant difference between incurable and curable diseases patients for their score of death anxiety. In table -2 the result of t-test revealed statistically no significant difference between the mean number of two groups were group-1 has ( $M=70.64)$ and the group -2 has ( 68.70) the t-value of t-test 0.21 is found to be statistically no significant. Its clear to accepted null hypothesis. It means although 
there is no significant difference in death anxiety of incurable and curable diseases patients. Ho-3 "There will not be any significant difference between incurable and curable diseases patients for their score of depression." To assess this hypothesis, t-test was used. The difference in the level of depression of incurable and curable diseases patients showed from Table -3. Comparison of mean scores between two groups showed that group-1 has $(M=27.83)$ and group-2 has $(22.17)$. The result of t-test applied between the mean scores of depression of comparative groups indicates that they differ statistically significant as the t-value of t-test is (2.11). Hence the null hypothesis also rejected and it is found that the depression level of incurable diseases patients is high than the curable diseases patients.

Table - 1 Showing results of $\mathrm{t}$ - value of psychological well being of two comparative Groups of patients

\begin{tabular}{|l|l|l|l|l|l|}
\hline Patients & No. & Mean & S.D. & t-value & Sig. \\
\hline $\begin{array}{l}\text { Incurable } \\
\text { Diseases }\end{array}$ & 40 & 21.89 & 1.91 & \multirow{2}{*}{4.4} & 0.01 \\
\hline $\begin{array}{l}\text { Curable } \\
\text { Diseases }\end{array}$ & 40 & 19.93 & 2.05 & & \\
\hline
\end{tabular}

Table -2 Showing results of $t$-value of death anxiety of two comparative groups of patients

\begin{tabular}{|l|l|l|l|l|l|}
\hline Patients & No. & Mean & S.D. & t-value & Sig. \\
\hline $\begin{array}{l}\text { Incurable } \\
\text { Diseases }\end{array}$ & 40 & 70.64 & 42.6 & \multirow{2}{*}{0.21} & N S \\
\hline $\begin{array}{l}\text { Curable } \\
\text { Diseases }\end{array}$ & 40 & 68.70 & 40.5 & & \\
\hline
\end{tabular}

Table - 3 Showing results of $\mathrm{t}$-value of depression of two comparative groups of patients

\begin{tabular}{|l|l|l|l|l|l|}
\hline Patients & No. & Mean & S.D. & t-value & Sig. \\
\hline $\begin{array}{l}\text { Incurable } \\
\text { Diseases }\end{array}$ & 40 & 27.83 & 12.7 & 2.11 & 0.05 \\
\hline $\begin{array}{l}\text { Curable } \\
\text { Diseases }\end{array}$ & 40 & 22.17 & 11.3 & & \\
\hline
\end{tabular}

\section{CONCLUSION :}

The main purpose of the present study was to investigated the difference of psychological wellbeing, death anxiety, depression between incurable and curable diseases patients. After analysis and interpretation the following conclusions were drawn. 
- The psychological well- being of curable diseases patients is significantly better than incurable diseases patients.

- As regarding the death anxiety, in curable diseases patients was not statistically significant different from that of patients of incurable diseases.

- The findings concluded that significant difference also observed between incurable and curable diseases patients regarding their score of depression.

\section{ACKNOWLEDGEMENT:}

The author of the present study sincerely acknowledge all the medical centers under the study and the under thank to all the patients who took part in the study for their time and kind cooperation, as well as author responsible entities which kindly helped in the study.

\section{REFERENCES:}

Dicker A, Armstrong D. (1995) Patients' views of priority setting in health care: an survey in one practice. $B M J ; 311: 1137$

Friedman H.J. (2002) Health psychology, prentice hall, New Jersary.

Garret, H. E. (1966) Statistic in Education and Psychology, Deep and Deep, Publication Pvt. Ltd.

Garret,H. B. (1996) Psychological Stress, New York, Academic press

Jawahri, A. \& Joseph, Temel, S. (2011) Does Palliative Care Improve Outcomes for Patients with Incurable Illness? A Review of the Evidence, The journal of supportive oncology, Vol. - 09, No. -3,May-June.

Kent, L. \& Shapiro, P. (2009). Depression and related psychological factors in heart disease.Harvard Review of Psychiatry, 17, 377-88.

Rappopart, Peros, Metelko, (2010) Environment and Disease Risk, American Association For the Advancement of Science, Vol. 330 Science.

Robinson, G. C. (2003) Anxiety disorders, Depression and Anxiety, 17, P. 180-184.

Sananda,\& Sajiman (2010) Anxiety and Depression in Ischeamic Heart Disease, Journal of the Indian Academy of Applied Psychology July 2010, Vol.36, No.2, 239-244.

-Shukla, K. C. (2005) Encyclopedic Dictionary of Psychology, Vol. - 1 -3, Pub. Ajey Verma For Commonwealth Publishers, Darya Ganj, New Delhi. 